$1-1-1965$

\title{
Cattle grub control experiments under field conditions using systemic and other insecticides, $1959-1965$
}

C. K. Dorsey

Follow this and additional works at: https://researchrepository.wvu.edu/ wv_agricultural_and_forestry_experiment_station_bulletins

\section{Digital Commons Citation}

Dorsey, C. K., "Cattle grub control experiments under field conditions using systemic and other insecticides, 1959-1965" (1965). West Virginia Agricultural and Forestry Experiment Station Bulletins. 515T.

https://researchrepository.wvu.edu/wv_agricultural_and_forestry_experiment_station_bulletins/660 @ WVU. It has been accepted for inclusion in West Virginia Agricultural and Forestry Experiment Station Bulletins by an authorized administrator of The Research Repository @ WVU. For more information, please contact ian.harmon@mail.wvu.edu. 
West Virginia University Libraries

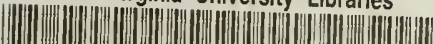

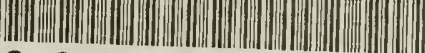

308021008961379 
Digitized by the Internet Archive in 2010 with funding from Lyrasis Members and Sloan Foundation 


\title{
THE AUTHORS
}

C. K. Dorsey is Entomologist; J. O. Heishman is Associate Animal Pathologist, and C. J. Cunningham Animal Husbandman in charge, Reymann Memorial Farms Sub-station; H. E. Kidder is Animal Husbandman.

\section{ACKNOWLEDGMENT}

The authors appreciate the assistance of Dr. Albert E. Drake, Acting Coordinator of Statistics, with statistical aspects of this study.

\author{
West Virginia University \\ Agricultural Experiment Station \\ College of Agriculture and Forestry \\ A. H. VanLandingham, Director \\ MoRGANTOWN
}




\section{Cattle Grub Control Experiments Under Field Conditions Using Systemic And Other Insecticides, 1959-1965}

C. K. DORSEY, J. O. HEISHMAN, C. J. CUNNINGHAM, and H. E. KIDDER

During the past ten years considerable emphasis has been given to the problem of controlling cattle grubs, Hypoderma spp., in cattle. Research programs in North America and other parts of the world have contributed much information and some effective methods to control these serious endoparasites.

Most workers agree that a community-wide approach for the control of these pests would be desirable and some programs have demonstrated the feasibility of this hypothesis (Scharff 1950; Riehl et al. 1965). Kühl (1958) speaks in terms of 95 per cent grub elimination in an area before permanent reductions in populations can be anticipated.

Cattle grubs are pests of persistent and serious concern to stockmen of West Virginia. Effective control measures which can be directed against the pests are important to cattle production in the State. Individual efforts rather than community programs must be relied upon. Scharff (1950) and the Livestock Conservation Incorporated report (1962) have emphasized economic losses resulting from attacks of cattle grubs on beef cattle.

The results of cattle grub control experiments conducted in West Virginia (1959-1965) are summarized in this bulletin. Various methods of administering insecticides were used-oral, spray, dust, pour-on, back rubber, back oiler, salt additive, and salt-feed additive applications. Some of the materials are recognized systemic insecticides; others included in the evaluation program were primarily applied for fly control purposes and are not generally considered as having basic, systemic characteristics. Certain insecticides in the latter category also produced significant reductions in cattle grub infestations.

\section{Methods of Application}

Insecticidal sprays were applied with power sprayers (125-150 p.s.i.) on the cattle after they had been introduced into a corral in numbers which permitted them to be easily moved around for thorough spray coverage. The angle of spray was approximately 90 degrees to the surface of the area of the body being treated. 
Dusts were applied, in measured amounts, by hand on the backs and sides of the cattle, which were restrained by halters. The dusts were rubbed in briskly.

Back rubber applications were effected by means of a three-cable, triangular arrangement with a salt box placed in the center of the triangle. They were maintained and re-charged with the fuel oilinsecticide mixture at weekly or 10-day intervals.

The back oiler treatments were applied from wicks (burlap and/or cotton) kept in an oily condition by a reservoir which contained the oilinsecticide mixture. The oilers were installed across doorways of milking barns in a manner permitting them to be rotated into position morning and night when the cows came in for milking ( 4 contacts daily). One installation was made in a field in which beef cattle were pastured. In this case a double chute arrangement was constructed with the salt box located in the center. An oiler was installed over the entrance of each chute.

The dust, back rubber and oiler treatments were part of experimental fly control programs.

Salt-insecticide mixture applications were made (free choice) in the field. The salt-feed insecticide mixtures were administered in feed boxes when the cattle came in from the field once daily for feeding.

Oral application of boluses was made with a balling gun.

\section{Method of Evaluating Effectiveness of Control Treatments}

The experimental cattle were examined twice each spring (midFebruary and mid-March) following treatment during the previous year. They were walked through a chute in order to palpate the entire surface of the back extending over the dorsal portions of the sides and back for the purpose of making grub counts.

\section{Insecticide Treatments-1959}

Five herds (yearling steers and heifers) totaling 90 animals (68 treated, 22 untreated) located in three widely separated areas of the State were selected as experimental animals for grub control applications. Four herds were treated with power spray ( 125 p.s.i.) application -two with coumaphos, 0.5 per cent; one with Neguvon (0,0-dimethyl 2,2,2-trichloro-1-hydroxyethyl phosphonate) 2.0 per cent; one with diazinon, 0.5 per cent. One herd was treated with Trolene (ronnel) boluses (37.5 gm./300 lbs.). All treatments except the diazinon spray gave satisfactory cattle grub reduction (Table 1, 1959). There were no symptoms of toxicity after any of the applications. 


\section{Insecticide Treatments-1960}

The 17 experimental herds comprised of 408 cattle ( 348 treated, 60 untreated) were located in four different areas of the State. Eleven herds were sprayed and six received pour-on treatments which were applied on the mid-dorsal area of the back. With the exception of one herd (No. 15), which was made up of mature cows, the animals were yearling steers and heifers.

One herd was sprayed with Ruelene ${ }^{\oplus}, 0.5$ per cent; two with dimethoate; one with coumaphos, 0.5 per cent; three with Neguvon, 1.0 per cent; two with diazinon, 0.1 per cent; one with ronnel, 1.0 per cent; and one with CP-10502, 1-(dimethoxy-phosphinyl) vinyl dimethyl phosphate, 0.5 per cent.

Two herds were treated with Ruelene 2.0 per cent pour-on applications, two with Tiguvon ${ }^{\otimes}, 0,0$-dimethyl 0- 4- (methylthio)-m-tolyl phosphorothioate, and two with coumaphos, 2.0 per cent. All pour-on mixtures were in water except those used on Herds 3 and 9 which were in mineral oil-the only ones in which signs of organophosphorus poisoning were noticed. The somewhat typical symptoms disappeared within 24 hours after the pour-on treatments of the animals.

All treatments produced excellent grub reductions (Table 2, 1960) except in the following: Herd 13 (Tiguvon, 0.5 per cent PO.), Herd 14 (Neguvon, 1.0 per cent spray), Herd 15 (ronnel 1.0 per cent spray), Herd 16 (diazinon, 0.1 per cent spray), and Herd 17 (CP-10502, 0.5 per cent spray). Drummond (1959) also achieved good grub control using dimethoate sprays.

\section{Insecticide Treatments-1961}

Nine herds (all yearlings) consisting of 307 cattle (252 treated, 55 untreated) were included in the experimental cattle grub control program this year. These animals, located in different areas of the State, had all been a part of experimental face and horn fly control programs.

Two herds received diazinon, 0.1 per cent spray treatments, and one received ronnel, 0.5 per cent spray application.

Two herds were treated with pour-on applications; 1 with coumaphos, 0.5 per cent; 1 with Ruelene, 0.5 per cent; 1 with carbaryl; and 1 with Neguvon, 0.5 per cent.

One herd was treated with carbaryl, 5.0 per cent dust (two applications).

Cattle grub reduction was good in all treatments (Table 3, 1960) except in Herd 5 (ronnel, 0.5 per cent spray); Herd 6 (carbaryl, 5.0 per cent dust); Herd 7 (carbaryl, 1.0 per cent pour-on); and Herds 8 and 9 (diazinon, 0.1 per cent spray). 
The pour-on mixtures were in water. There were no toxicity symptoms observed among treated animals in 1961.

\section{Insecticide Treatments-1962}

The 16 experimental herds, selected from different areas of the State, included 732 cattle (627 treated and 105 untreated). All animals were yearlings except Herds 16 and 21 which were mature cows.

Two herds were treated with Ruelene, 12.5 per cent pour-on mixtures; 4 with Famophos ${ }^{\circledR}$ ([0-p-dimethylsulfamoyl] phenyl, 0,0-dimethyl phosphorothioate), 16.7 per cent pour-on; and 2 with Tiguvon, 1.0 per cent pour-on.

One herd made four contacts daily with a Ciodrin ${ }^{\circledR}, 0.75$ per cent back oiler, and one herd had free choice access to a Ciodrin, 0.75 per cent, three-cable back rubber. One herd was treated with an $\operatorname{Imidan}^{(0)}(0,0,-$ dimethyl S-phthalimidomethyl phosphorodithoate) back rubber.

Two herds were administered coumaphos-salt mixtures $(0.5 \mathrm{mg} . /-$ $\mathrm{kg}$./hd./day) over a three-month period. In the case of one herd the selection. was free choice, for the other the mixture was applied in the feed. One herd received Famophos ( $1 \mathrm{mg} . / \mathrm{kg} . / \mathrm{hd} . /$ day $)$ free-choice selection in the field, in salt.

All of the pour-on treatments gave good cattle grub control results (Table 4, 1961) except the treatments in Herd 11 (Tiguvon, 1.0 per cent pour-on) and in Herd 13 (Neguvon, 16.7 per cent pour-on).

Kohler and Rogoff (1962) observed good reduction in cattle grubs after using Famophos with the pour-on method. Brethour and Harvey (1962) reported effective control of grubs using methoxychlor, Ruelene, coumaphos applied by means of back rubbers.

Prolonged contact with back rubbers charged with Ciodrin (Herds 14 and 10) and with Imidan (Herd 12) during the months of June, July, and August produced significant reduction in cattle grub infestations.

There were no observable symptoms of toxic effects following any of the treatments used this year.

\section{Insecticide Treatments-1963}

A total of 457 cattle ( 333 treated and 124 untreated) in 14 herds located in three different areas of the State were selected for experimental cattle grub control studies. All animals were yearlings except in two herds (10 and 12) which were mature cows.

Four herds received pour-on treatments of coumaphos, 4.0 per cent and 2 herds 2.0 per cent; three herds Neguvon, 16.0 per cent; and two herds 8.0 per cent pour-on applications. 
One herd was treated with Ciodrin-dichlorvos ( 1.0 per cent-0.25 per cent) back oiler ( 4 contacts daily) and one herd with a three-cable, free-choice, back rubber charged with the same mixture.

One herd was fed coumaphos ( $2 \mathrm{mg} . / \mathrm{kg} . / \mathrm{hd} . /$ day $)$ salt-feed mixture once daily for three months.

Excellent cattle grub reduction was observed in all treatments except in Herd 14 (coumaphos, $2 \mathrm{mg} . / \mathrm{kg} . / \mathrm{hd} . /$ day salt-feed treatment) (Table 5, 1963).

There were toxicity symptoms observed this year in all herds treated with coumaphos ( 2.0 per cent and 4.0 per cent factory-prepared pour-on formulations). The animals treated with these mixtures evidenced extreme discomfort for a brief period (30 minutes) after which symptoms (arching the back, urinating, defecating, lying down, getting up) disappeared.

Turner (1962) observed good grub control using coumaphos and Neguvon pour-on applications.

\section{Insecticide Treatments-1964}

One herd consisting of 30 yearlings was treated during the horn fly season (June, July, and August) with Ciodrin ( 2.0 per cent livestock spray formulation) applied with a reservoir-type back oiler equipped with wicks. An oiler was installed at each end of a double-ended chute which had a salt box located in the center. This treatment was applied for two purposes-to evaluate the effectiveness of this method in face fly and horn fly control and to observe the effect on reducing cattle grub infestations in the treated animals.

In 1962 and 1963 significant ( 1.0 per cent level) reductions in cattle grub numbers were observed (Tables 4 and 5 ) in herds treated with various Ciodrin mixtures applied with oilers and back rubbers. Significant reductions in cattle grubs were also evident in 1964-65 ( 46.0 per cent reduction) in the Ciodrin-treated herd (back oiler applications) (Table 6, 1964).

Another group ( 72 head) of cattle which had been a part of an experimental fly control program during the summer of 1964 was treated for cattle grub control with pour-on applications of either Ciodrin 2.0 per cent or dichlorvos 1.0 per cent livestock spray formulations. These treatments were started on November 11 and were continued at weekly intervals for four weeks. The rates and numbers of applications varied. The animals were treated as they walked through a chute. The kind of treatment which they had received during the summer was determined after the pour-on cattle grub treatments had been completed.

The results of cattle grub reductions following the pour-on applications (1964) using Ciodrin or dichlorvos, apparently confounded by the 
various fly control treatments, were not conclusive. This apparent influence of the several fly control treatments on cattle grub control is more obvious than that exhibited as the result of Ciodrin or dichlorvos pour-on treatments.

Animals which received Baygon 2.0 per cent dust or Tiguvon 2.0 per cent back rubber (oil) applications for fly control and the NovemberDecember (1964) pour-on grub control treatments were free from cattle grubs except for one animal (Table 6). The cattle treated for fly control with guthion 2.0 per cent back rubbers followed by the pour-on treatments were the only animals (11 out of 13) which had grubs present ( 2 to 7 per animal) though in small numbers (Table 7 and 8 , 1964).

\section{Discussion}

The most effective insecticides applied as high pressure sprays (100-150 p.s.i.) were coumaphos, Neguvon, Ruelene, and dimethoate. Coumaphos, Ruelene, Famophos and Neguvon, applied by the pour-on method, also produced excellent cattle grub control results.

In these studies insecticides administered in salt or salt-feed mixtures were, in general, not satisfactory. This could have been in part because of erratic and inconsistent consumption observed in the case of some of the experimental animals. Harvey and Brethour (1961) reported good grub control using Ruelene as a feed additive.

Cattle which had received certain treatments (spray, back rubber, oiler and pour-on) for face fly and horn fly control during the summer had fewer grubs than animals which had not received fly control treatments. This was true when insecticides recognized as systemic (coumaphos, Ruelene, Famophos) were used and also in cases where insecticides not recognized as having primarily systemic characteristics (Ciodrin, diazinon, Imidan, carbaryl, and dichlorvos) were applied (Tables 1-8). In the latter category, even though grub control was not as good generally as when systemics were applied, the effect was one of benefit in addition to fly control. It would be desirable to know more about the mode of action of insecticides against endoparasites such as the cattle grubs, particularly those not recognized as having systemic characteristics.

Goulding and Taylor (1962) reported an extended mortality effect on grub control in cattle treated with Dibrom ${ }^{\oplus}$ (1,2-dibromo-2,2-dichloroethyl phosphate). Dichlorvos is a degradation product of Dibrom. Drummond (1963) found that dichlorvos as a feed additive was effective against Gasterophilus larvae.

These workers (Goulding and Taylor) were of the opinion that the 
effect was not systemic with respect to mode of action; however, they did not offer a satisfactory alternative explanation. It is difficult to reconcile the results of these studies with any other recognized mode of action, if the mode of action is not systemic.

In the case of cattle which received overall spray treatments there could have been a repelling and/or residual effect on heel fly adults visiting the lower portions of the animals. The animals treated with back oilers or back rubbers did not have the same type of protection because the lower parts of their bodies were not treated.

Observable toxicity symptoms appeared only in animals treated with the pour-on method (coumaphos, Ruelene) in 1960 and 1963. These were transitory manifestations and they disappeared within 24 hours or less without any therapeutic treatment of the affected animals.

\section{SUMMARY AND CONCLUSIONS}

In the experimental cattle grub control program reported in this bulletin, there were 63 different herds comprising 2,104 animals (1,730 treated and 374 untreated) included in the study. These animals were treated with a number of different insecticides using spray, pour-on, dusting, back rubber, oiler and oral methods of application.

Spray and pour-on applications are quite effective when certain insecticides are correctly applied. Pour-on applications require less equipment, waste less material and are easy to apply. Toxicity symptoms are more likely to occur unless dosage rate, animal weight and health are carefully considered.

Spray treatments for grub control require power equipment. They are quite wasteful of insecticidal material, and in general are more expensive to apply.

Excellent cattle grub control results were accomplished using coumaphos, Ruelene, dimethoate and Neguvon applied as sprays; coumaphos, Ruelene, Famophos and Neguvon applied as pour-on treatments; and Ruelene as a bolus-type of application.

Application of insecticides prepared in bolus form are the most difficult to use and the treatment often results in throat injury to the animal.

Cattle which had received certain treatments for face and horn fly control during the summer (back rubber, spray, oiler and pour-on methods) had fewer grubs than animals not receiving fly control treatments. This was true of some insecticides whether they were true systemics or whether their systemic characteristics were questionable (Ciodrin, diazinon, dichlorvos and Imidan). 


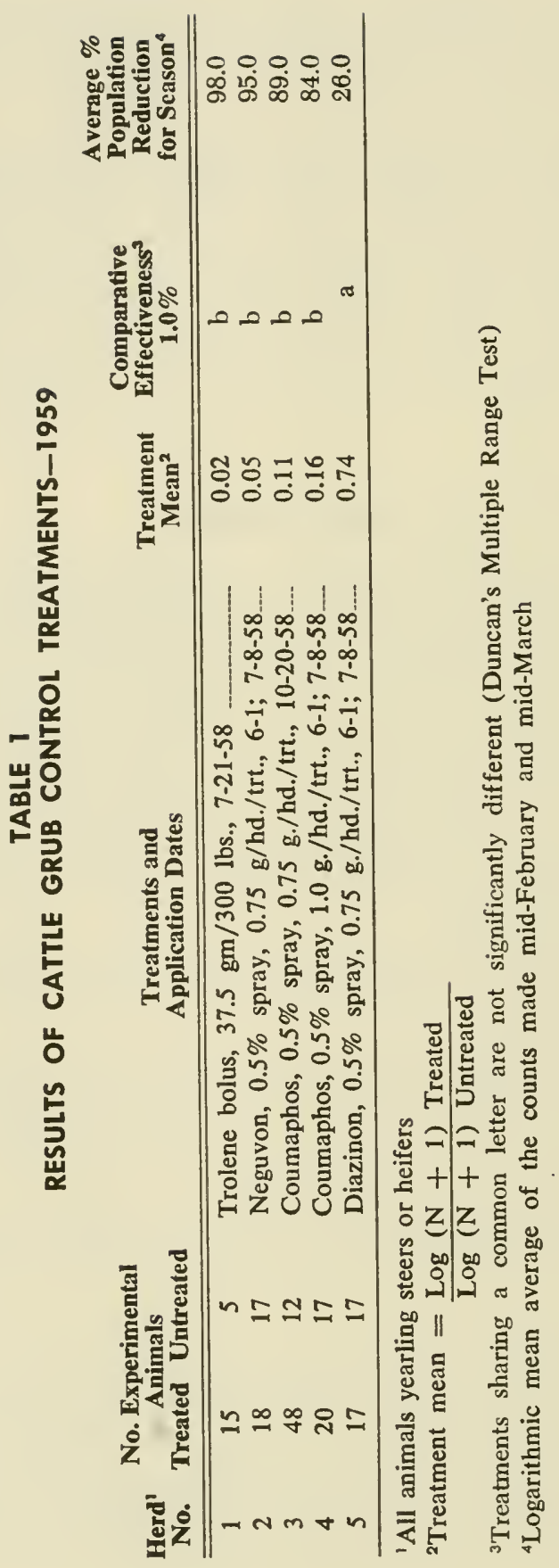




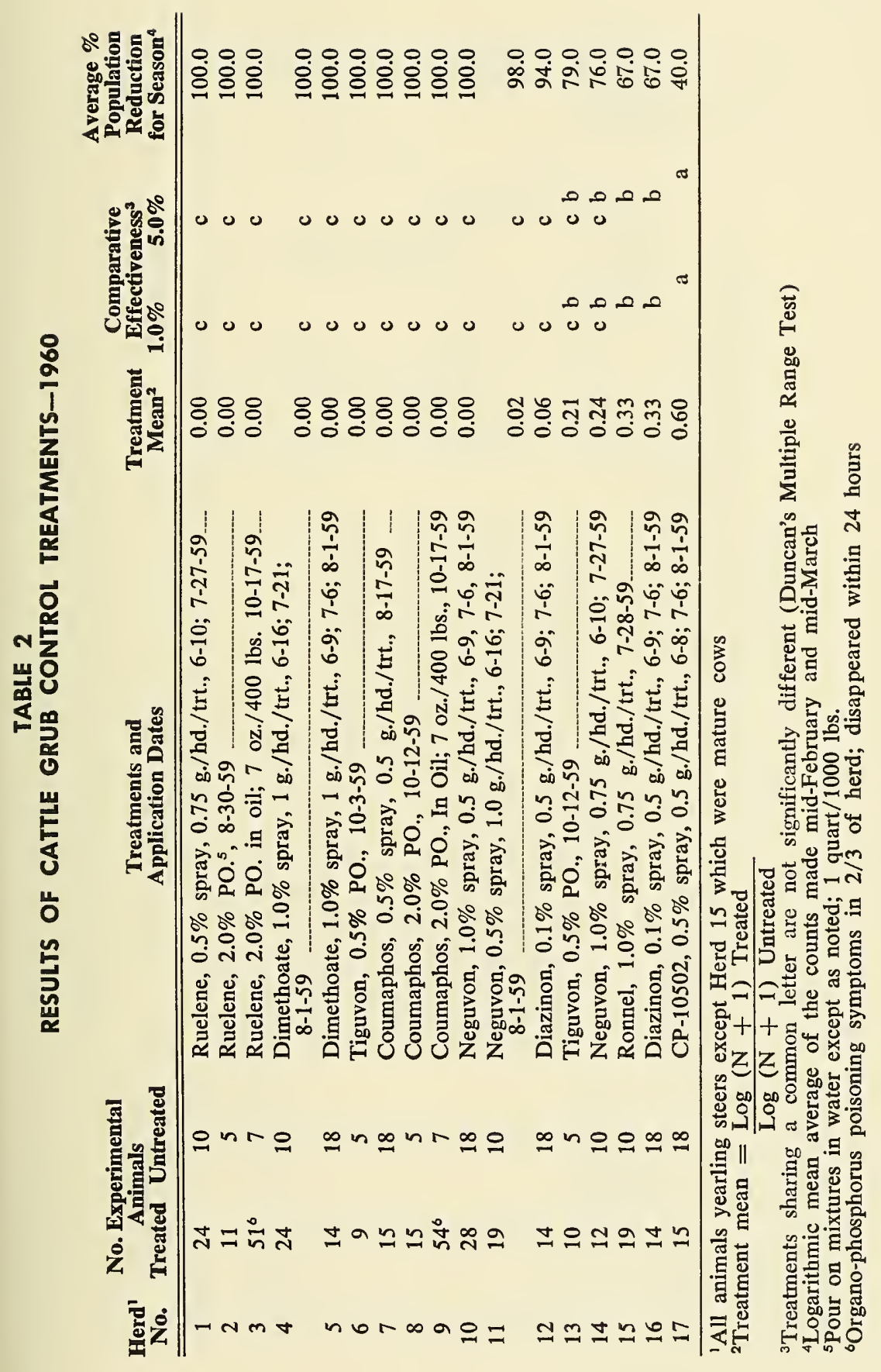




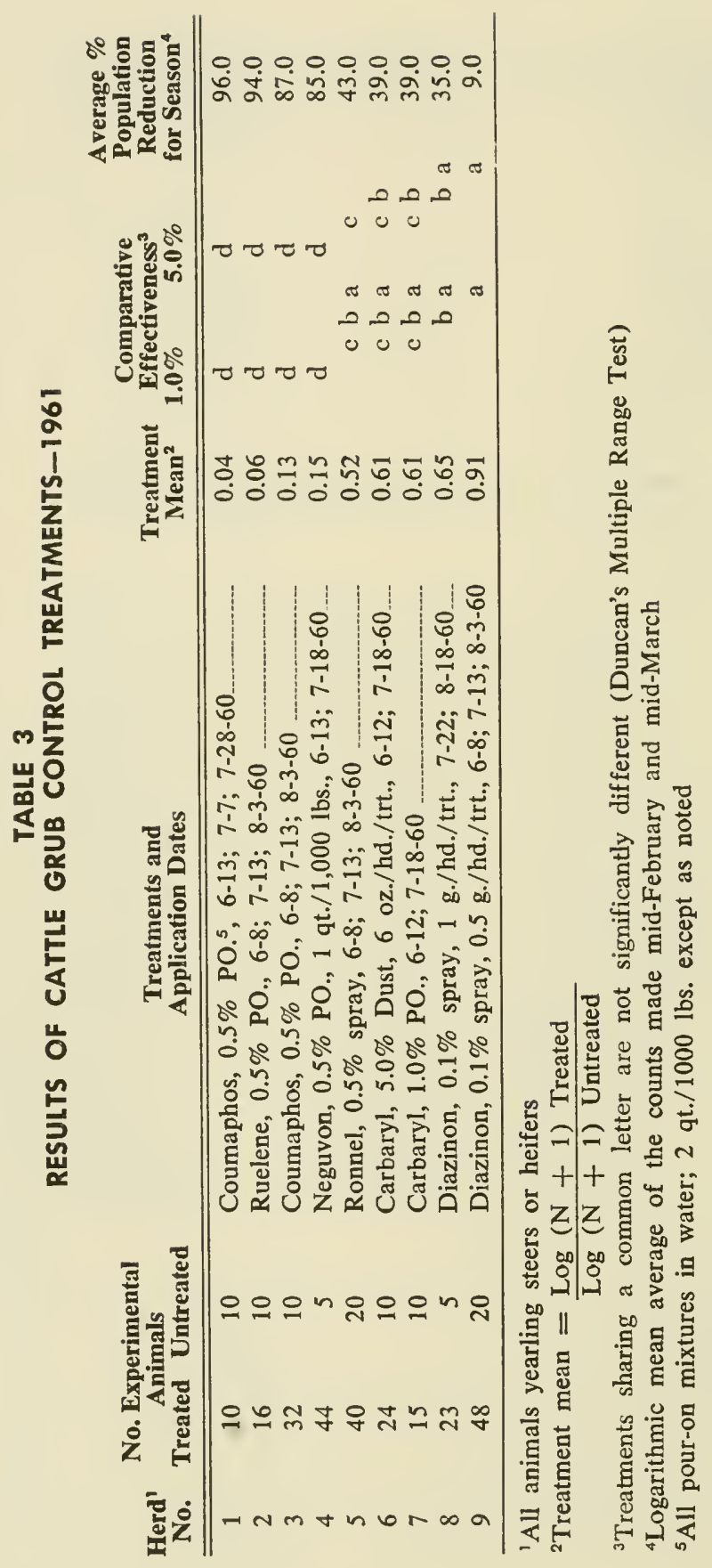




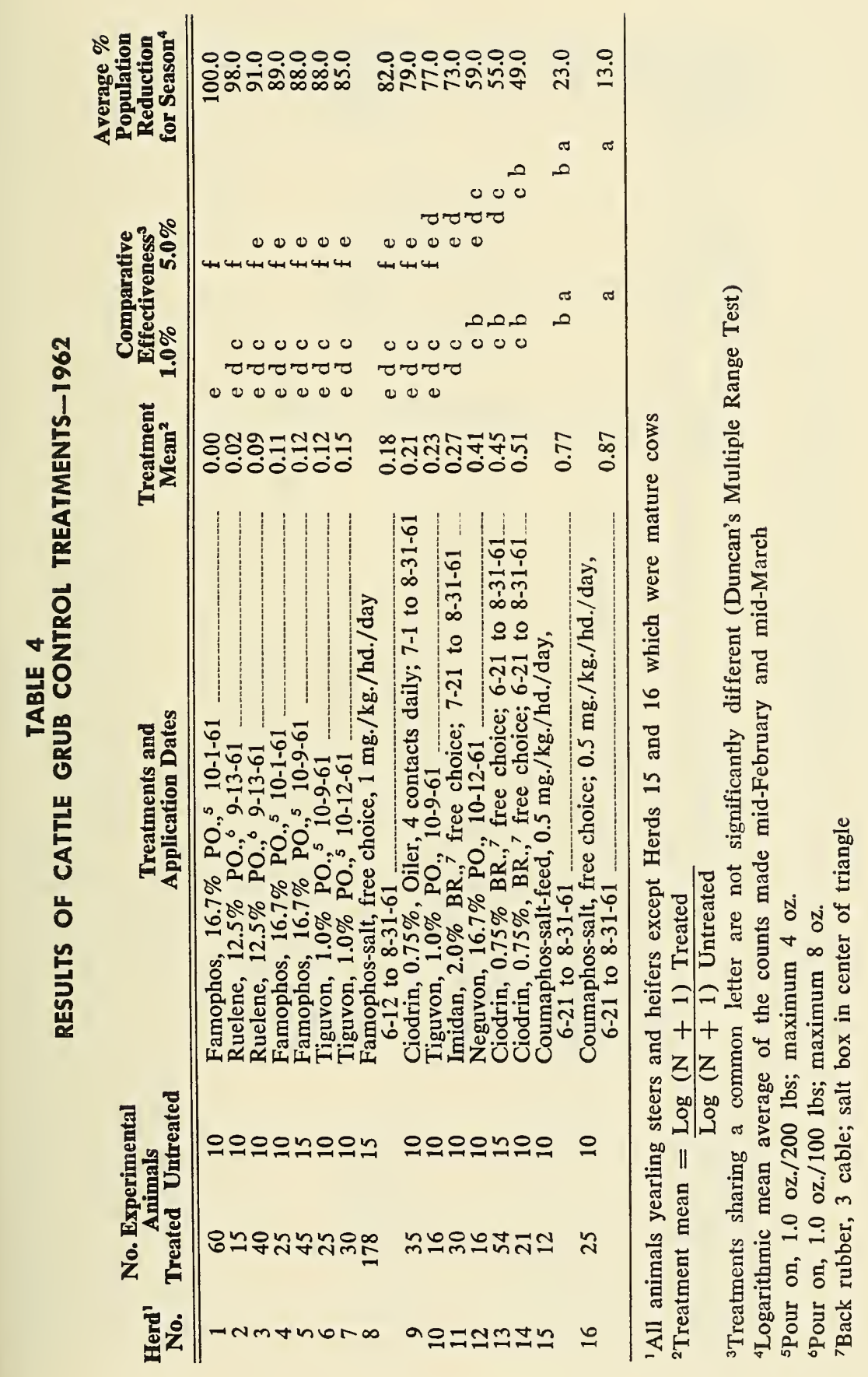




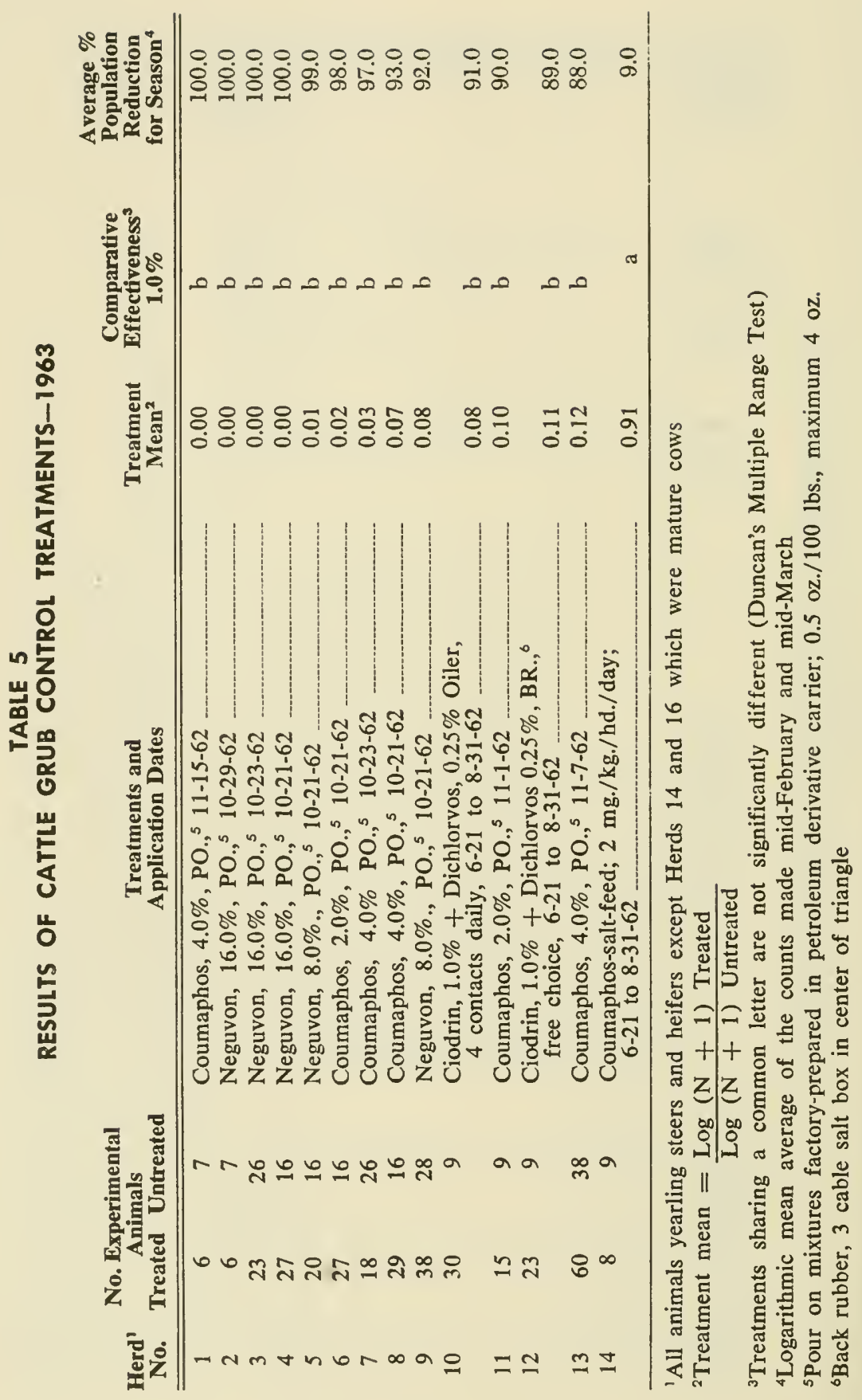




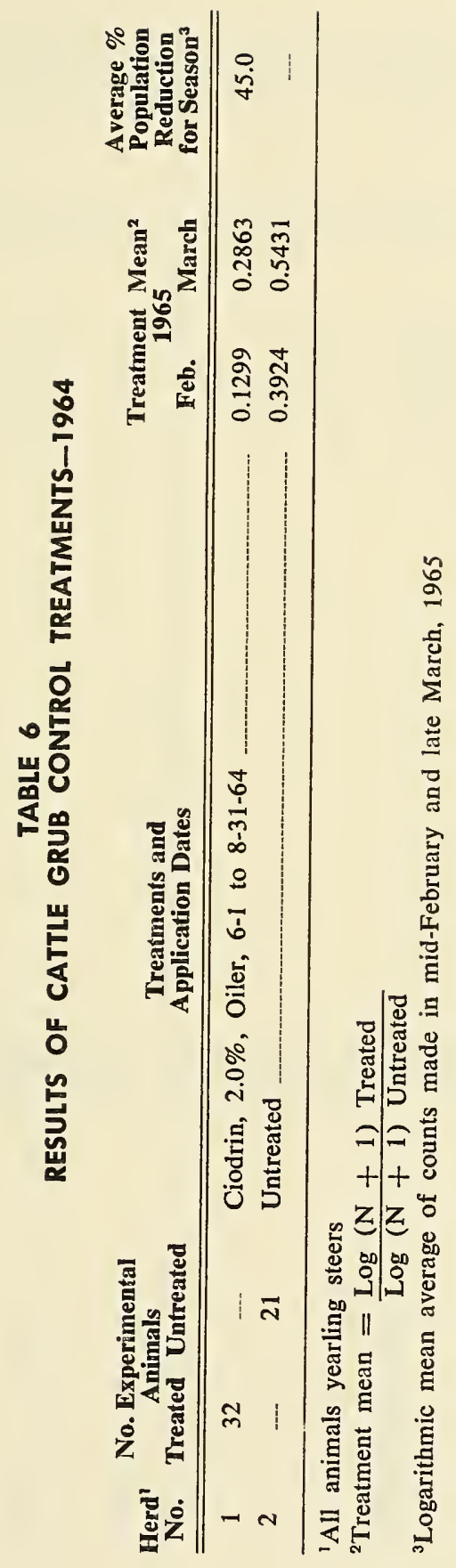




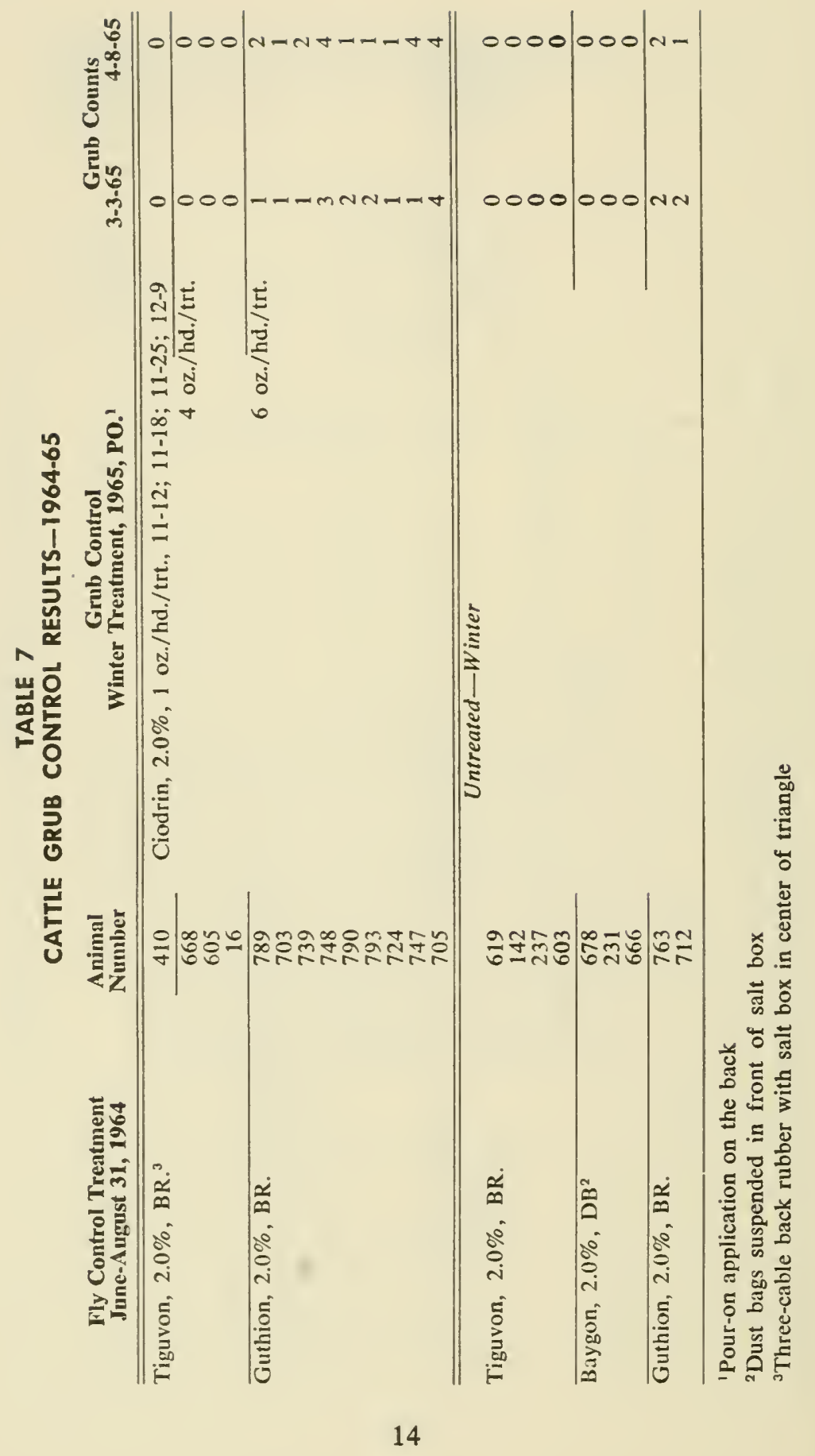



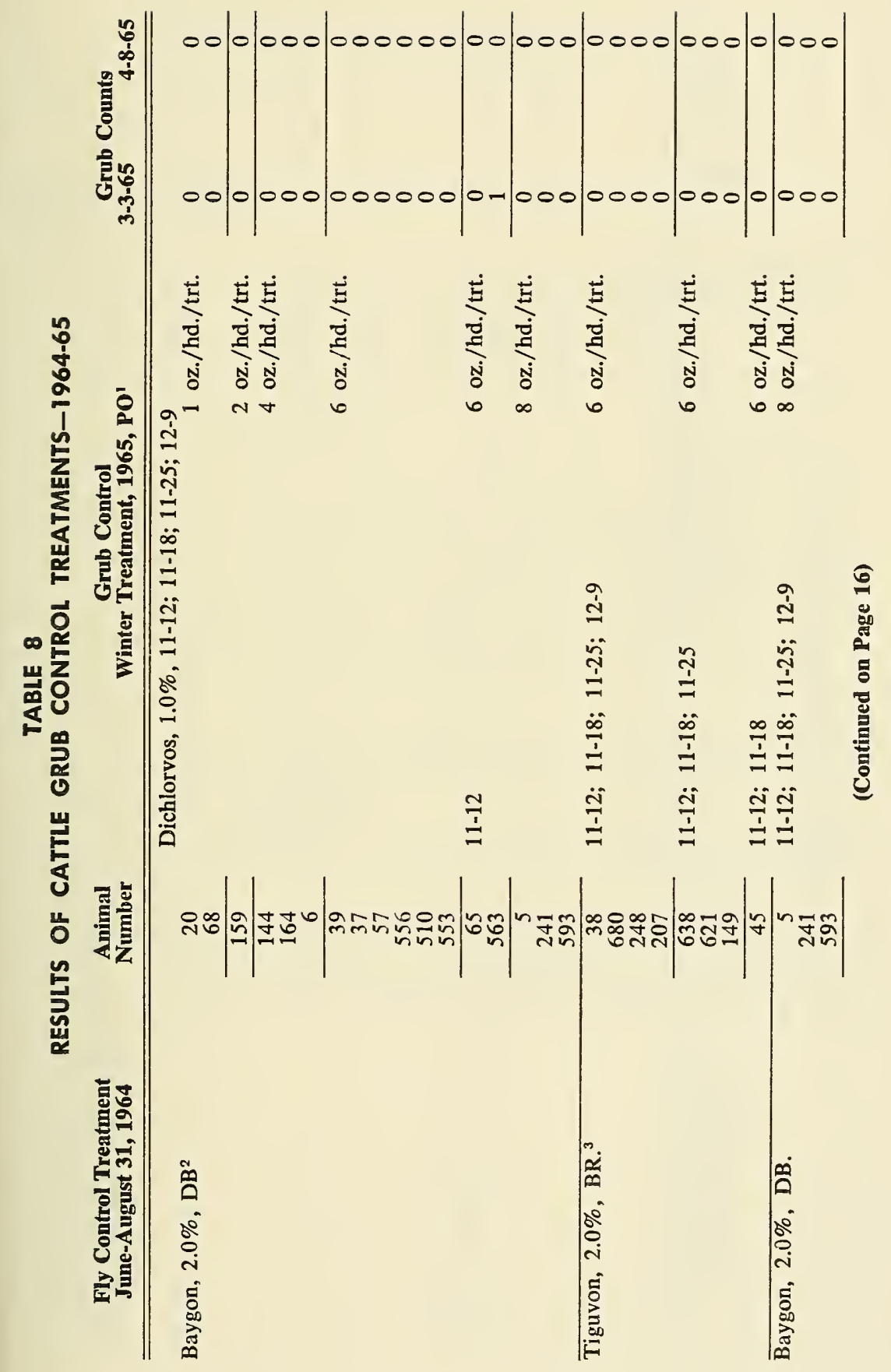

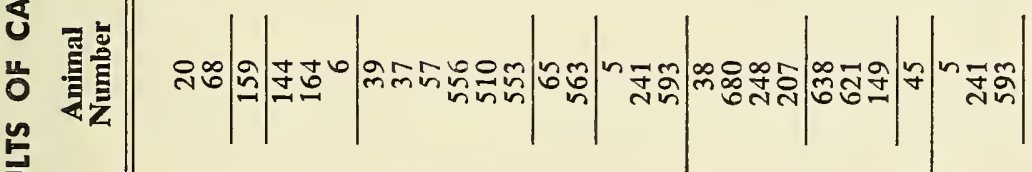

旨

10

흡금 ஸे

出司豆

- 尼豆 三 


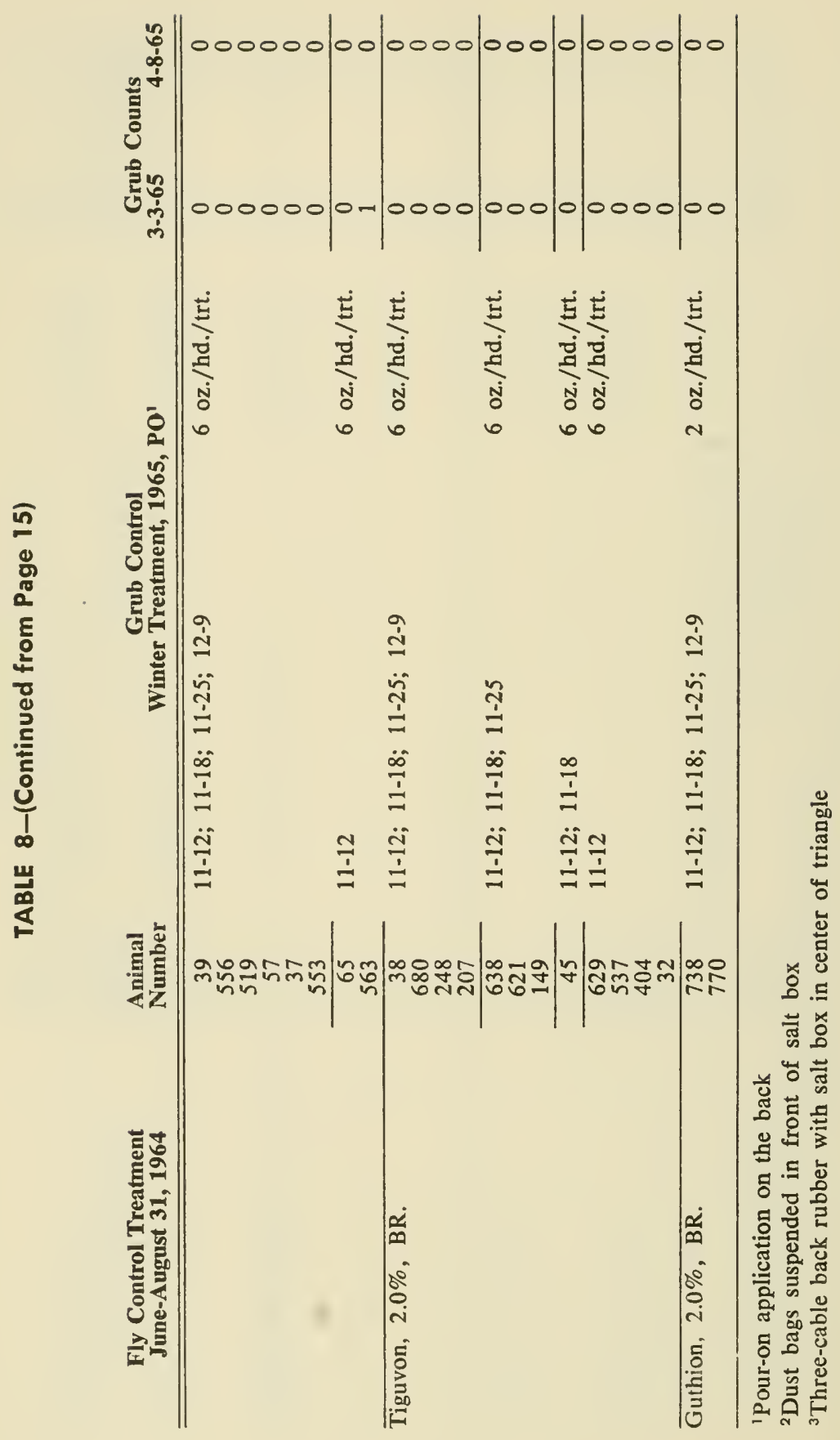




\section{Liferafure Cifed}

Brethour, J. R. and T. L. Harvey. 1962. Effects of certain systemic insecticides in back rubbers for cattle grub control. J. Econ. Entomol. 55(5):811-2.

Drummond, R. O. 1963. Tests with systemic insecticides for the control of Gasterophilus larvae in horses. J. Econ. Entomol. 56(1):50-2.

Drummond, R. O. 1959. Tests with dimethoate for systemic control of cattle grubs. J. Econ. Entomol. 52(5):1004-6.

Drummond, R. O. and B. Moore. 1958. Ronnel sprays for systemic control of cattle grubs. J. Econ. Entomol. 51(5):1028-9.

Goulding, R. L. and N. O. Taylor. 1962. Effects of topical applications of dibrom upon cattle lice and cattle grubs. J. Econ. Entomol. 55(5):774-6.

Harvey, T. L. and J. R. Brethour. 1961. Effectiveness of ruelene and ronnel for ear tick compared with cattle grub control. J. Econ. Entomol. 54(4):814-5.

Kohler, P. H. and W. M. Rogoff. 1962. Control of cattle grubs by pour-on, injection and spray. J. Econ. Entomol. 55(4):539-44.

Kühl, R. 1958. Der gegenwärtige Stand der Dasselfliegenforschung. Zeitchr. angew. Ent. 43:77-99.

Livestock Conservation Incorporated. 1962. (The Dow Chemical Company, Armour and Company and Ruser and Sons). Results and performance data on Dow systemic grub control products. Report by Dow Chemical Company, Texas Division, Freeport, Texas.

Riehl, L. A., H. W. Lembright and P. D. Ludwig. 1965. Area population control of heel flies by ruelene pour-on application annually to cattle. J. Econ. Entomol. $58(1): 1-4$.

Scharff, D. K. 1950. Cattle grubs, their biologies, their distribution and experiments in their control. Montana State College Agr. Exp. Sta. Bull. 471, 74 pp.

Turner, E. C., Jr. 1962. Spray and pour-on application of systemic insecticides for control of cattle grubs in Virginia J. Econ. Entomol. 55(4):564-5. 
(1)

apoloman

anto 